\title{
Clinical Study of the Success Rate of Dental Treatments under General Anesthesia in Children Referred to Hamadan School of Dentistry from 2015 to 2017
}

\author{
Farzad Mojarad $^{1}$, Ali Aghajani ${ }^{2}$, Ghodratallah Roshanaei ${ }^{3}$, Fahimeh Daneshyar $^{2}$ \\ 1. Associate Professor, Department of Pediatric, School of Dentistry, Hamedan University of Medical Sciences, Hamedan, \\ Iran. ORCID ID: 0000-0001-9947-5222 \\ 2. Post-Graduate Student, Department of Pediatric, School of Dentistry, Hamedan University of Medical Sciences, Hamedan, \\ Iran., ( Correspondinf Author ), Tel: +989132754054, E-mail: Ali_dnt.2000@yahoo.com, ORCID ID: 0000-0001-8691-3940 \\ 3. Associate Professor, Department of Statistics, Faculty of Public Health, Hamedan University of Medical Sciences, \\ Hamedan, Iran. ORCID ID:0000-0002-3547-9125 \\ 4. Post-Graduate Student, Department of Pediatric, School of Dentistry, Hamedan University of Medical Sciences, Hamedan, \\ Iran. ORCID ID: 0000-0003-3233-6521
}

\begin{abstract}
Background and Aim: General anesthesia is an important approach to control low-aged children with specific problems who need wide teeth restoration operations. The aim of this study is to evaluate the success rate of dental treatments under general anesthesia in children referred to Hamadan School of Dentistry from 2015 to 2017.

Materials and Methods: This is a descriptive-cross-sectional study in which 60 patients referred to the pediatric department of Hamadan School of dentistry received dental treatment services under general anesthesia from 2015 to 2017. Then, they were examined after 6 months of their treatment. The cases were checked-up on the dental engine using a Dental Mirror and Explorer and success or failure data were recorded in a special form designed for each case. Data were analyzed using SPSS 14, and a statistical model of logistic regression and the Chi-square test was used to compare the success ratio of dental treatments.

Results: The success rate of pulp treatments i.e. pulpotomy and pulpectomy are high (98\%). Regarding the treatment of posterior teeth, stainless steel cover is the most successful treatment with a failure rate of $1.5 \%$. The failure rate of SSC is significantly lower than amalgam filling $(8.06 \%)(\mathrm{p}=0.004)$. Regarding anterior teeth, one-surface composite filling with a failure rate of $5.5 \%$ and anterior build-up with a failure rate of $10.7 \%$ have the lowest and the highest failure rates, respectively.

Conclusion: Among the restoration operations, SSC under general anesthesia is considered as the selective technique due to its high success rate.
\end{abstract}

Keywords: General Anesthesia, Dental Treatment, Success Rate

Received: Mar 5, $2019 \quad$ Accepted: Oct 28, 2019

How to cite the article: Farzad Mojarad, Ali Aghajani, Ghodratallah Roshanaei, Fahimeh Daneshyar. Clinical Study of the Success Rate of Dental Treatments under General Anesthesia in Children Referred to Hamadan School of Dentistry from 2015 to 2017 SJKU 2020;25(1):112-119.

Copyright (C) 2018 the Author (s). Published by Kurdistan University of Medical Sciences. This is an open access article distributed under the terms of the Creative Commons Attribution-Non Commercial License 4.0 (CCBYNC), where it is permissible to download, share, remix, transform, and buildup the work provided it is properly cited. The work cannot be used commercially without permission from the journal 


\title{
بررسى بالينى ميزان موفقيت درمانهاى دندانيزشكى تحت بىهوشى عمومى در كودكان مراجعه كننده به دانشكده دندانيز شكى همدان دور سال هان
}

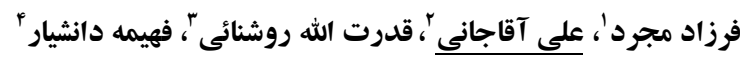

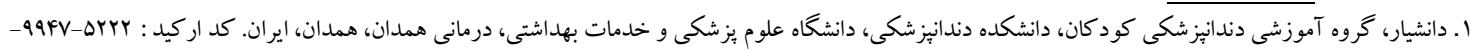

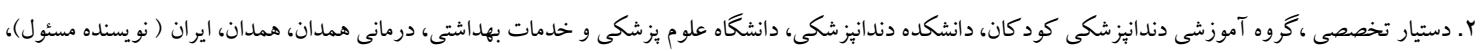

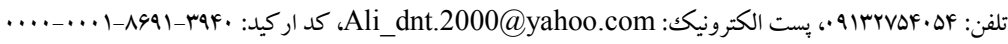

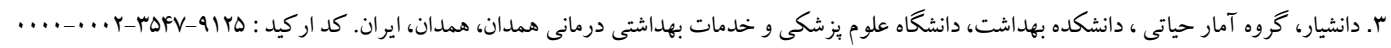

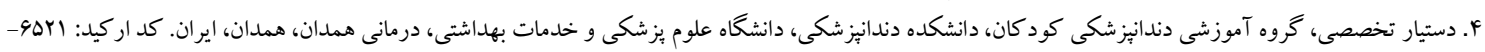

جָكيله

زمينه و هدف: بىهوشى عمومى يكى از روشهاى مهم براى كنترل كودكان كم سن يا با مشكلات خاص است كه نيازمند

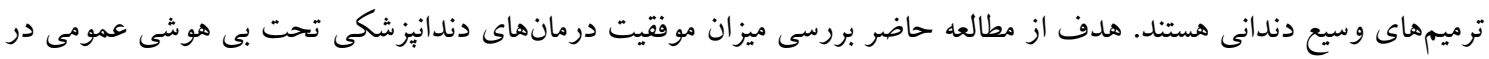

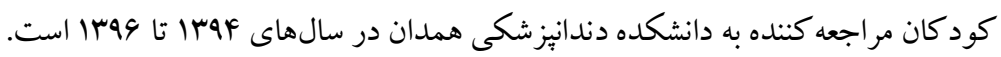

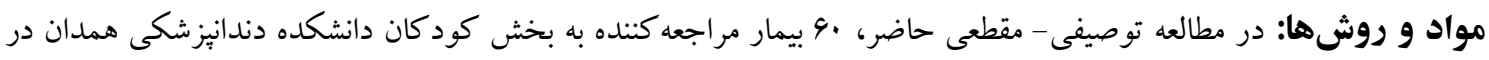
سالهاى 99-94

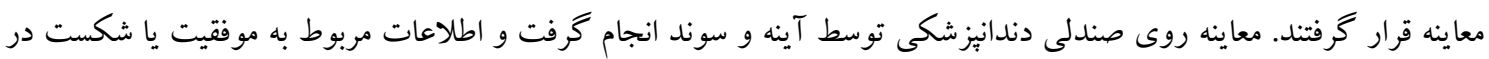

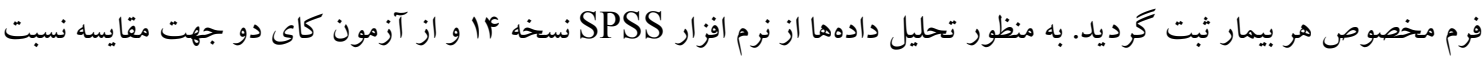
موفقيت درمانهاى دندانيز شكى مختلف استفاده شد.

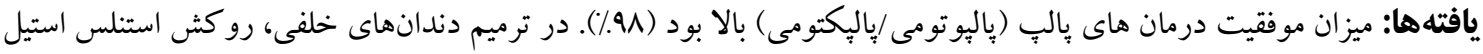
با ه/1/ (SSC)

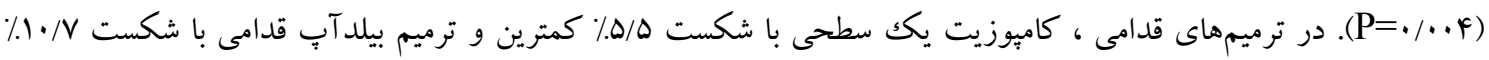
درصد بيشترين شكست را داشت.

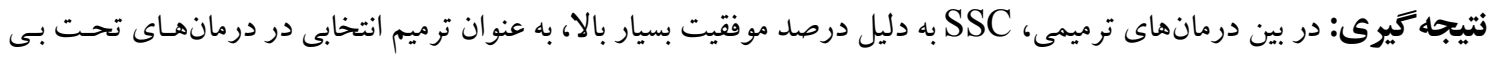

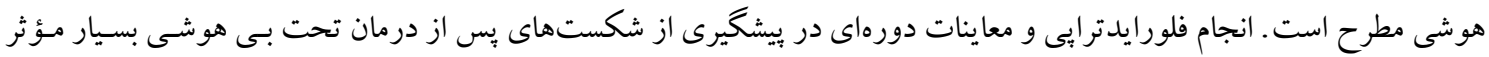


كذشته معرفى شده است و در برخى از بيماران بىهوشى

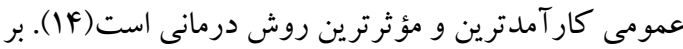
اساس نظر آكادمى دندانيزشكى كودكان آمريكا بيماران خاصى كه توانايى تحمل درمانهاى (AAPD) معمول دندانيزشكى را نداشته باشند، توسط بىهوشى لئى عمومى تحت درمان قرار مى گيرند(ه). از مزاياى انجام درمانهاى دندانبز شكى تحت بىهوشى عمومى مى توان به درمان ايمن و كار آمد و مناسب، همجِنين درمانهاى وسيع تنها در يكك جلسه درمانى با حداقل ناراحتى براى بيمار و استرس ذهنى و جسمى كمتر براى بيمار و دندانيز شكك اشاره كرد(19-19) . بىهوشى عمومى يك شرايط ايدهآل را براى درمانهاى ترميمى دندانيز شكى ايجاد مى كند، مانند حداقل

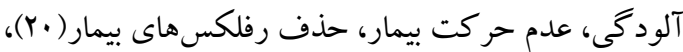
در مقالات مختلف موفقيت كلينيكى بالايى براى روكث آثرائ استنلس استيل گزارش شده است(Y-Y-IY).و حندين مطالعه كذشتهنگر موفقيت كلينيكى بالايى را براى اين درمان (91\%)

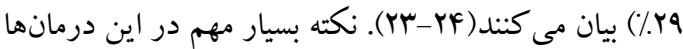
اين است كه، با صرف زمان كوتاهتر، مطمئنترين درمان براى بيمار انجام شود(YD). با توجه به اين كه بيمارانى كه به

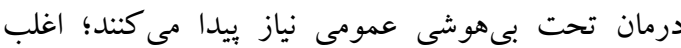
بهداشت دهانى ضعيفى دارند و با توجه به هزينه بالا و

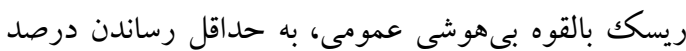
موارد شكست درمان در طى زمان اهميت ويزماى خواهد

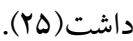

هدف از مطالعه حاضر بررسى ميزان موفقيت درمانهاى دندانيز شكى انجام شده تحت بى هوشى عمومى در كود كان

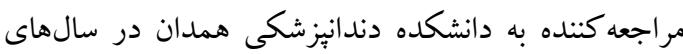

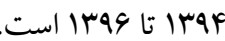

مواد و روشها - (- ماد
مقدمه يوسيدگى وسيع دندانها در كودكان از جمله مشكلات بهداشتى به خصوص در جوامع در حال توسعه است كه در

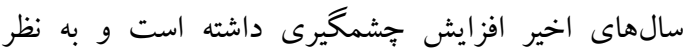
مىرسد اين افزايش به شدت تحت تأثير رزيمغذايى بوده آندا است. اين مسئله مىتواند خواب، تغذيه و سلامت كودك را

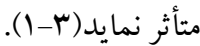
در بسيارى از كودكان مىتوان درمانهاى دندانيزشكى را توسط تكنيككهاى شكلدهى رفتار غيروابسته به دارو مانند تكنيك Tell-Show-Do به صورت مناسبى انجام داد؛ اما در برخى كود كان با نيازهاى درمانى بيجيجيده (غيرهمكار) بيماران نارس از نظر ذهنى يا فيزيولوزيكى و بيماران داراى مشكلات يزشكى گسترده، اقدامات دندانيزشكى تحت شرايط خاصى مانند استفاده از آرامبخشى با كاز نيتروس

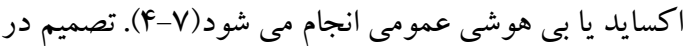

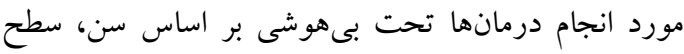

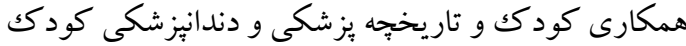

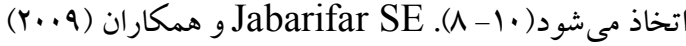
در مطالعه خود به بررسى كيفيت زندگى كود كان دريافت-

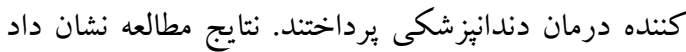
كه درمان دندانِيز شكى تحت بىهوشى در كود كان خردسال غيرهمكار با مشكلات دندانى وسيع باعث بهبود كيفيت

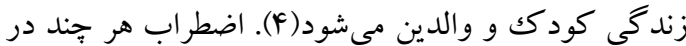
درجات اندكك مىتواند باعث مراجعات نامنظم و عدم ييكيرى درمان گردد، در سطح وسيعتر باعث مشكلات عديدهاى همجون اختلال در خواب، افكار منفى و احساس دراس درن

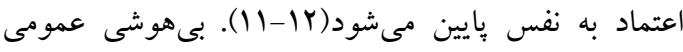

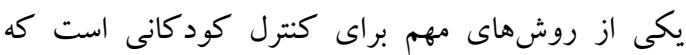
نيازمند ترميمهاى وسيع و جراحى هاى دندانى هستند و اغلب مانب

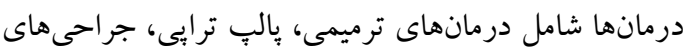
كوجكك و كشيدن دندان است(r|). بىهوشى عمومى در

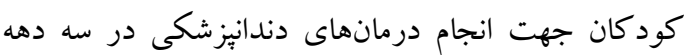

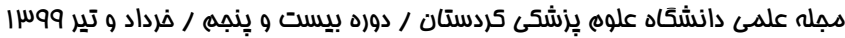




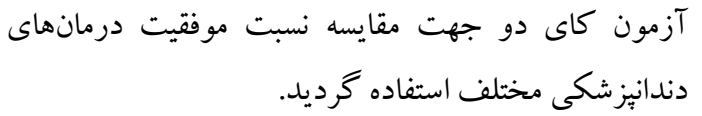

كافته ها

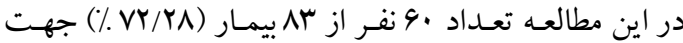
معاينه مراجعه نمودند كه از اين تعداد هب نفر مذكر و اY نفر مؤنث بودند. ميانگين سنى كود كان در مرحله درمـان تحـت بى هوشى عمومى هو ماه و در زمان معاينـه او مـاه بـود. بسين ميـزان شكست درمـانهـاى ترميمسى و درمـانهـاى بِالـب بـا

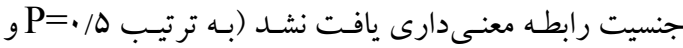
9) نفر تشنج، س نفر بيمارى قلبى) مبتلا بودند. رابطه بين شكست درمانهاى پِالٍ و ترميمى با وجود بيمارى سيستميك معنى -

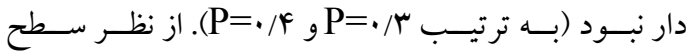
تحصيلات، بدران تحصيلات دانشـاهى بـالاترى نسبـت بـه مادران داشتند، ميزان تحصيلات اغلب والـدين ليسـانس بـود

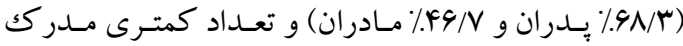

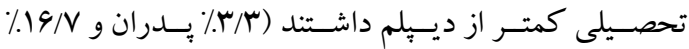

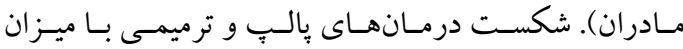
تحصيلات يـدر (Y/Y دارى نداشت. تكرار درمانهاى انجام شده بعد از بى هوشى در زمان معاينه ها/1 درصـد گَزارش شـد. ارتبـاط شكسـت درمانهاى يالٍ و ترميمى با تعداد دفعـات مسـواكك زدن در روز، انجام فلورايدتر ايى دورهاى و معاينات دورهاى معنى دار بود ( اس.//P=. (P=). در مطالعه حاضـر بـه دليـل مشـخصنبـودن نوع درمان يالٍ (ياليوتومى /ِالֶٍكتومى) انجام شده در يرونده كود كـان و عـدم تهيـهـ راديـو گر افى در افـراد مـورد مطالعـه،

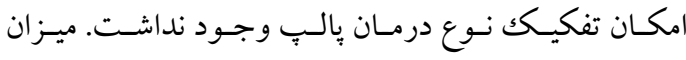

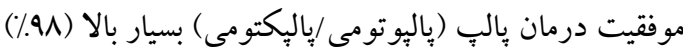
بود كه يـس از تهيـه راديـو گر افى از هـ دنـدان دجهـار مشـكل شده، مشخص كرديد كه در زمان بـى هوشى تحـت درمـان ياليوتومى قرارگر فته اند؛ بـه عبـارتى ميـزان شكسـت درمـان
در مطالعه توصيفى-مقطعى حاضر تعداد 94 بيمار مر اجعه كننده به بخش تخصصى كود كان دانشكده دندانيزشكى همدان در سالهاى 99-1M9F كه درمانهاى دندانيزشكى تحت بى هوشى را دريافت كرده و حداقل 9 ماه از درمان آنها گخذشته بود مورد معاينه قرار كرفتند. با والدين اين كودكان تماس كرفته شد و يس از توضيح نحوه كار، در صورت تمايل والدين براى معاينه و انجام فلورايد ترايى نوبتدهى انجام شد. معيارهاى خروج از مطالعه بيمارانى بودند كه بس از تماس گرفتن و نوبتدهى به كلينيك مراجعه ننمودند يا به دليل مسافت زياد قادر به شركت در اين مطالعه نبودند. در هر جلسه درمانى تعداد ب بيمار انتخاب شد تا زمان كافى جهت معاينه دقيق و فلورايدترايى وجود داشته باشد. معاينه توسط رزيدنت دندانيزشكى كود كان (يكك معاينه گر) و بر روى صندلى بلى دندانيزشكى با استفاده از سوند و آينه و نور يونيت دندانيزشكى صورت كرفت(Y4). معاينه به طور معمول از خلفى ترين دندان كوادرانت راست بالا شروع شده و يس از معاينه ماكزيلا به آخرين دندان سمت راست منديبل ختم مىشد واطلاعات بيماران و نتيجه معاينات در فرم مربوط به هر بيمار ثبت گرديد. در صورت مشاهده موارد بوسيدكى جديد يا شكست درمان، نوبتدهى جهت درمان در بخش تخصصى كود كان انجام مى گرفت. همجنين در اين مطالعه دندانهاى دائمى به دليل كمى تعداد و نداشتن ارزش آمارى از مطالعه خارج شدند. وجود آبسه، لقى غير طبيعى و فيستول در دندانهاى با درمان بِالٍ و التهاب لثه، نابجايى روكش، افتادن و يا لقى روكش در دندانهاى روكش شده شكست درمان محسوب مىشد. و هم جنين براى بررسى شكست ترميمهاى آمالكام و كاميوزيتى از معيار Ryge كه شامل سه يارامتر تطابق لبهاى، از دست رفتن ترميم و پيوسيدكى ثانويه است استفاده گرديد(YV). به منظور تجزيه وتحليل دادهها و بررسى نتايج از نرم افزار SPSS نسخه fl و و از 
ميزان شكست ترميم آمالكام و ميزان شكست SSC معنى -

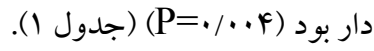

مقادير تطابق لبهاى، از دست رفتن ماده ترميمى و يوسيدگى

Ryge ثانويه ترميمهاى آمالكام و كاميوزيت طبق معيارهاى

$$
\text { به دست آمد و در جدول ب ثبت گرديد }
$$

جدول ا. نوع درمان، ميزان شكست و ميزان موفقيت

\begin{tabular}{|c|c|c|c|}
\hline كل & ميزان موفقيت & ميز ان شكست & نوع درمان \\
\hline $\operatorname{lrf}(1 \cdot \cdots)$ & $11 f(91 / 94)$ & $1 \cdot(1 / \cdot 9)$ & ترميم آمالكام \\
\hline $90(1 \cdots)$ & AF $(A M / F T)$ & $11(11 / \Delta \mathrm{V})$ & ترميم كاميوزيت قدامى \\
\hline $\operatorname{rr}(1 \cdots)$ & PI (9Y/91) & $1(r / T \Lambda)$ & PRR \\
\hline $119(1 \cdots)$ & $1199(9 / / 41)$ & $r(1 / \Delta \Lambda)$ & SSC \\
\hline$r \Delta \cdot(1 \cdots)$ & TYD (१A) & $\Delta(r)$ & "ِاليوتومى / پالٍكتومى \\
\hline
\end{tabular}

جدول r. ميزان تطابق لبهاى، از دست رفتن ترميم و يوسيدكى ثانويه بر اساس Ryge criteria در ترميمهاى كاميوزيت و آمالكام

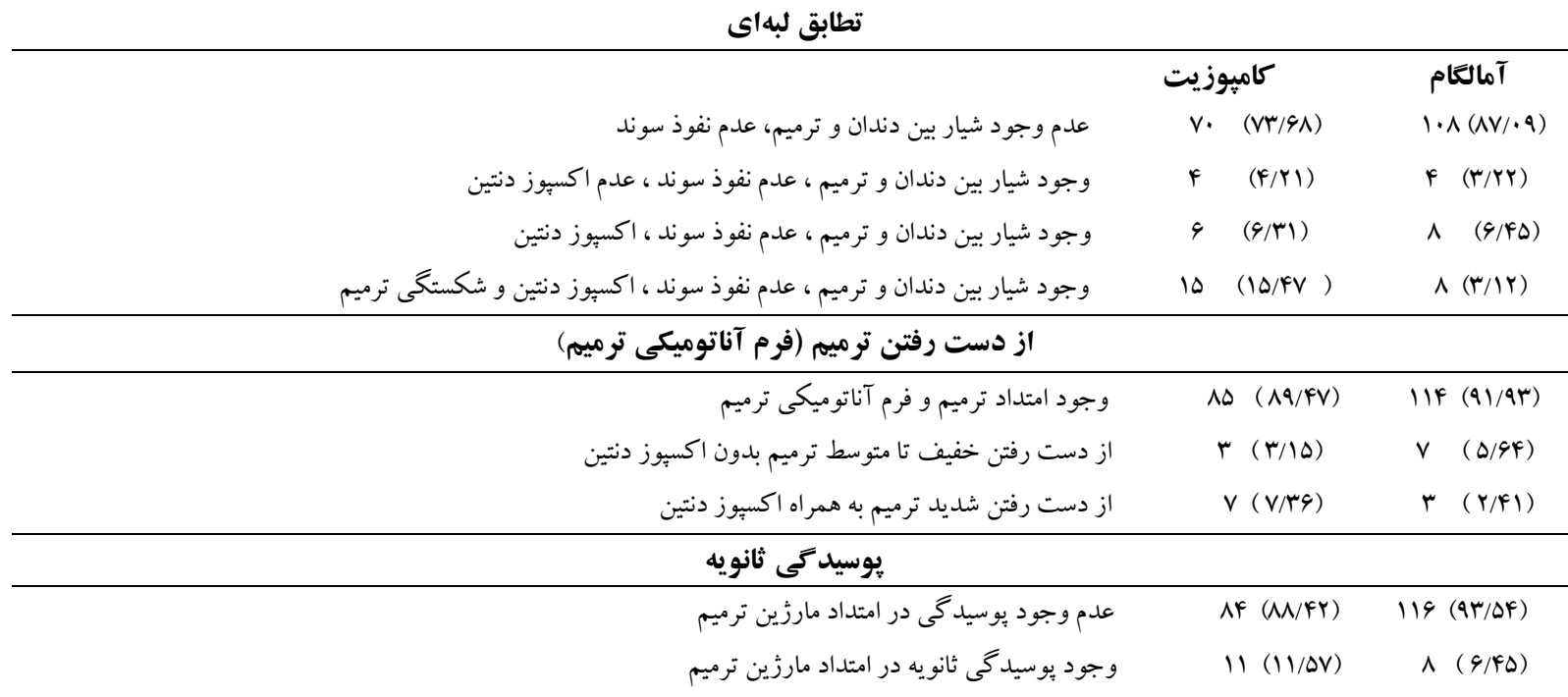

است .به همين دليل و با توجه به نياز گروه كثيرى از بحث

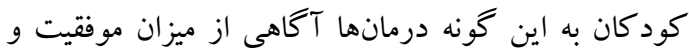
در سالهاى اخير، انجام درمانهاى دندانيزشكى كودكان شكست روشهاى درمانى مختلف و در نتيجه تلاش در تحت بى هوشى عمومى، بهطور روز افزون افزايش يافته

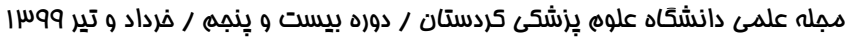


على آقا هانى

شكست ه/1\%، موفقترين درمان محسوب شدند و شكست

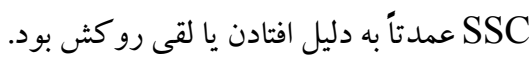

ميزان موفقيت درمان بالبوتومى و بالِكتومى در مطالعه انجام

شده با مطالعهى Eshghi و همكاران (r. (Y) و و مطالعهى KHodadadi و همكاران (Kar Ir) مشابهت

داشت(Y Y و YY). با مقايسه درمانهاى پِالٍ انجام شده تحت

بى هوشى عمومى در مطالعات مختلف، موفقيت بالاى آنها را مىتوان به علت انجام كار در يكك محيط بىاسترس و و كنترل بهتر كودكى و امكان ايزولاسيون بهتر ناحيه جهت

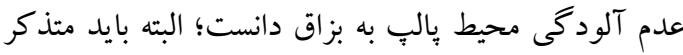

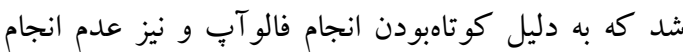
راديو گرافى در زمان معاينه يّيخيرى ممكن است درصد موفقيت كلينيكى اين درمانها بالاتر از مقدار واقعى آن كزارش شده باشد.

ميزان نياز به درمان مجدد در مطالعه حاضر (ه//1\%) بسيار

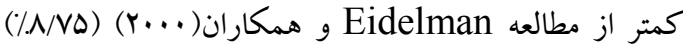
كزارش شد(YV) كه علت بالاتربودن نياز به درمان مجدد را، حساسيت بالاى معاينه كننده در تعيين موارد شكست بيان

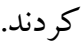
در اين مطالعه ميزان شكست درمانهاى بيلدآب كاميوزيت قدامى (19/) كه از مطالعه KHodadadi و همكاران

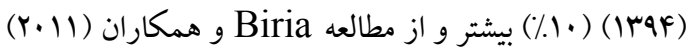

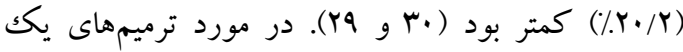
سطحى و دوسطحى كاميوزيت قدامى نتايج مشابه مطالعه KHodadadi

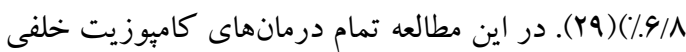

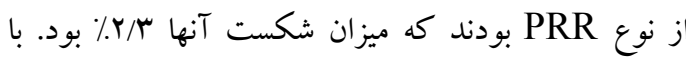

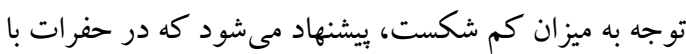
يوسيدكى جزئى ترميم PRR به كار رود. نتايج تحقيقات كذشته نيز استفاده از PRR را مطلوب دانسته اند(ب مور ·r).
جهت بهبود شيوه ارائه خدمات درمانى تحت بى هوشى عمومى امرى ضرورى است. انديكاسيون اصلى بسيارى از درمانهاى دندانِيزشى تحت بى هوشى عمومى، عدم

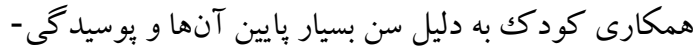
هاى وسيع در سطوح مختلف دندانى بيان گرديده

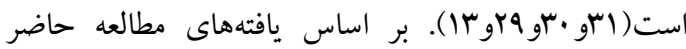
متوسط سنى كودكان در مرحله درمان تحت بى هوشى لهى عمومى qه ماه بود كه نشاندهنده بِايين بودن سن اكثريت آنها است. از ميان افراد مورد مطالعه اكثريت آنها (9ه/) مذكر بودند؛ كه مشابه ديخر مطالعه انجام شده در زمينه دندانيز شكى تحت بى هوشى عمومى است( •r).

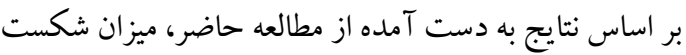
درمانهاى بِالٍ و ترميمى با ميزان تحصيلات والدين مرتبط نبود. در مطالعه KHodadadi و همكاران (F (IF) ميزان شكست ترميمهاى انجام شده با ميزان تحصيلات مادر مرتبط بود و با افزايش تحصيلات مادر، شكست درمانهاى ترميمى كمتر بود(9). در مطالعه حاضر ارتباط بين ميزان شكست درمانهاى بِالٍ و ترميمى با معاينات دورهاى و و

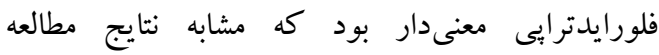
KHodadadi

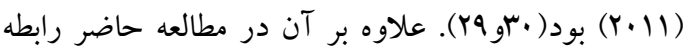
معنىدارى بين ميزان شكست درمانهاى بالٍٍ و ترميمى و تعداد دفعات مسواكززدن در روز مشاهده شد. اين موارد

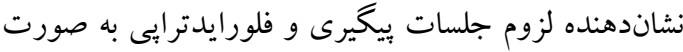
منظم است. ميزان شكست ترميمهاى آمالكام در مطالعه

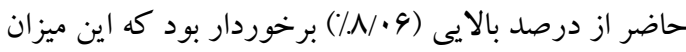
مشابه مطالعه Eshghi و همكاران (Y/. Y) و كمتر از مطالعه (1991) O'Sullivan و همكاران (r...rote بود (اساو צYو اYY): كه علت آن مىتواند استفاده از SSC در

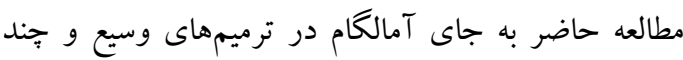
سطحى باشد. در مطالعه حاضر ترميمهاى SSC با ميزان

\section{نتيجه كيرى}

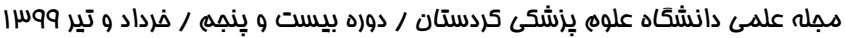




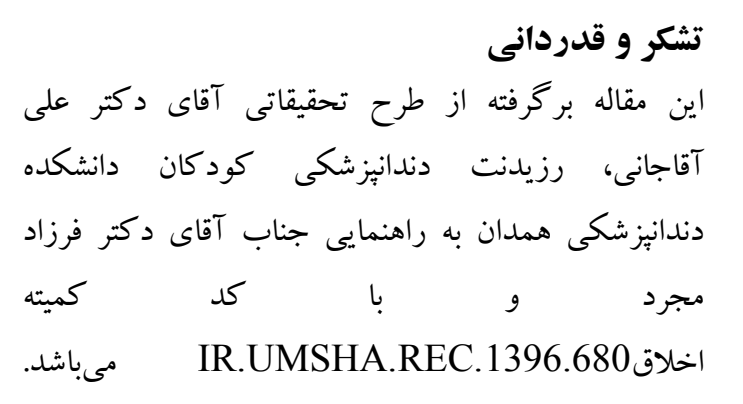

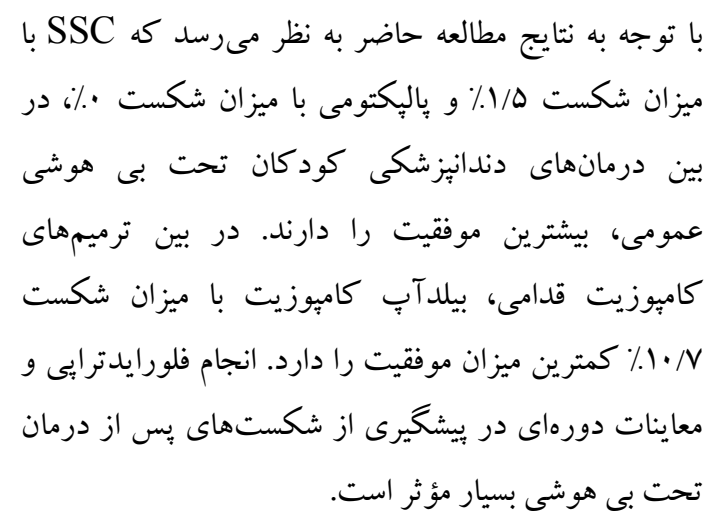

منابع

1. Low W, Tan S, Schwartz S. The effect of severe caries on the quality of life in young children. J Pediatr Dent.1999; 21(6): 325-6.

2. Milnes AR. Description and epidemiology of nursing caries. J Public Health Dent. 1996; 56(1): 3850 .

3. Pitts NB, Boyles J, Nugent ZJ, Thomas N, Pine CM. The dental caries experience of 5-year-old children in England and Wales. Surveys co-ordinated by the British Association for the Study of Community Dentistry.CDH. 2007;24(1):59-63.

4. Jabarifar SE, Eshghi AR, Shabanian M, Ahmad S. Changes in children's oral health related quality of life following dental treatment under general anesthesia.J Dent Res. 2009;6(1):13-16.

5.American Academy of Pediatric Dentistry. Council on Clinical Affairs-Guideline on behavior guidance for the pediatric dental patient. J Pediater Dent. 2005-2006;27:92-100 .

6.Roeters J, Burgersdijk R. The need for general anesthesia for the dental treatment of mentally handicapped patients: a follow-upstudy. ASDC J Dent Child. 1984;52(5):344-6.

7.Enger DJ. A survey of 200 pediatric dental general anesthesia cases. ASDC J Dent Child. 1985;52:36-41.

8.Vermeulen M, Vinckier F, Vandenbroucke J. Dental general anesthesia: clinical characteristics of 933 patients. ASDC J Dent Child. 1990;58(1):27-30.

9.Stanková M, Buček A, Dostálová T, Ginzelová K, Pacáková Z, Seydlová M. Patients with special needs within treatment under general anesthesia-meta-analysis. Prague Med Rep. 2011;112(3):216-25.

10.AffairsAoPDCoC. Guideline on management of dental patients with special health care needs. J Pediater Dent. 2008-2009;30:107-11.

11.Voytus ML. Evaluation, scheduling, and management of dental care under general anesthesia forspecial needs patients. Dent Clin North Am. 2009;53(2):243-54.

12.Hagglin C, Hakeberg M, Ahlgwist M, Sullivan M, Berggren U. Factors assocciated with dental anxiety and attendce in middle-aged and elderly women community. Dent Oral Epidemiol.2000; 28(6): 451-60.

13.Cohen SM, Fiske J, Newton JT. The impact of dental anxiety on daily living. Br Dent J 2000; 189(10): 385-90. 
14.Çolak H, Dülgergil ÇT, Dalli M, Hamidi MM. Early childhood caries update: a review of causes, diagnoses, and treatments. J Nat Sci Biol Med. 2013;4(1):29-38.

15.Thikkurissy S, Crawford B, Groner J, Stewart R, Smiley MK. Effect of Passive Smoke Exposure on General Anesthesia for Pediatric Dental Patients. Anesth prog. 2012;59(4):143-6.

16.Chia-Ling Tsai B, Yi-Ling Tsai B, Yng-Tzer Lin B, Yai-Tin Lin B. A retrospective study of dental treatment under general anesthesia of children with or without a chronic illness and/or a disability. Chang Gung Med J. 2006;29(4):412-8.

17.Lee J, Roberts M. Mortality risks associated with pediatric dental care using general anesthesia in a hospital setting. J Clin Pediatr Dent. 2003;27(4):381-3.

18.Anderson H, Drummond B, Thomson W. Changes in aspects of children's oral-health-related quality of life following dental treatment under general anaesthesia. Int $\mathrm{J}$ Pediatr Dent. 2004;14(5):317-25.

19.Wilson S. Pharmacological management of the pediatric dental patient. J Pediatr Dent. 2004;26(2):131-6.

20.Atan S, Ashley P, Gilthorpe M, Scheer B, Mason C, Roberts G. Morbidity following dental treatment of children under intubation general anaesthesia in a day-stay unit. Int $\mathrm{J}$ Pediatr Dent. 2004;14(1):9-16.

21.Tate AR, Ng MW, Needleman H, Acs G. Failure rates of restorative proceduresfollowing dental rehabilitation under general anesthesia. J Pediatr Dent. 2002;24(1):69.

22.Roberts J, Attari N, Sherriff M. The survival of resin modified glass ionomer and stainless steel crown restorations in primary molars, placed in a specialist paediatric dental practice. Br Dent $\mathrm{J}$. 2005;198(7):427-31.

23.Atieh M. Stainless steel crown versus modified open-sandwich restorations for primary molars: a 2-year randomized clinical trial. Int J Pediatr Dent.2008;(5)18:325-332.

24.Attari N, Roberts J. Restoration of primary teeth with crowns: a systematic review of the literature. Eur Arch Paediatr Dent. 2006;1(2):58-62.

25.Randall RC. Preformed metal crowns for primary and permanent molar teeth: review of the literature. J Pediatr Dent. 2002;24(5):489-500.

26.Eshghi A, Samani MJ, Najafi NF, Hajiahmadi M. Evaluation of efficacy of restorative dental treatment provided under general anesthesia at hospitalized pediatric dental patients of Isfahan. Dent Res J. 2012;9(4):478.

27. Eidelman E, Faibis S, Peretz B. A comparison of restorations for children with early childhood caries treated under general anesthesia or conscious sedation. J Pediatr Dent. 2000;22(1):33-7.

28. Sheller B, Williams BJ, Hays K, Mancl L. Reasons for repeat dental treatment under general anesthesia for the healthy child. J Pediatr Dent. 2003;25(6):546-52.

29.KHodadadi E, KHafari S, Kuhestany F. Failure assessment of pediatric dental treatment under general anesthesia. J Res Dent Sci. 2015; 12 (3):137-144.

30.Biria M, Ansari G, Taheri Z. Failure rate of dental procedures performed under general anesthesia on children presenting to mofid pediatric hospital during 2010-2011.JDS.2012:30(1):1-8.

31. O'Sullivan EA, Curzon ME. The efficacy of comprehensive dental care for children under general anesthesia. Br Dent J. 1991;171(2):56.

32.Elliot R, Roberts MW, Burkes J, Phillips C. Evaluation of the carbon dioxide laser on vital human primary pulp tissue. J Pediatr Dent. $1999 ; 21: 327-31$.

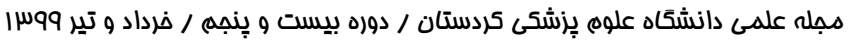

